\title{
Urgences
}

\section{Le droit inaliénable à l'information... culturelle}

\section{Bernard Boucher}

Numéro 11, 3e trimestre 1984

URI : https://id.erudit.org/iderudit/025168ar

DOI : https://doi.org/10.7202/025168ar

Aller au sommaire du numéro

Éditeur(s)

Urgences

ISSN

0226-9554 (imprimé)

1927-3924 (numérique)

Découvrir la revue

Citer cet article

Boucher, B. (1984). Le droit inaliénable à l'information... culturelle. Urgences, (11), 7-14. https://doi.org/10.7202/025168ar d'utilisation que vous pouvez consulter en ligne.

https://apropos.erudit.org/fr/usagers/politique-dutilisation/ 


\title{
CHRONIQUE
}

LE DROIT INALIÉNABLE À L'INFORMATION... CULTURELLE

\author{
BERNARD BOUCHER
}




\section{LE DROIT INALIÉNABLE À L'INFORMATION... CULTURELLE}

La question de la présence des sujets dits d'intérêt culturel dans les médias n'est pas nouvelle. Depuis qu'il existe un système d'information, il va sans dire qu'il a toujours été fait une place à la culture. Une telle place se devait d'avoir une importance variable selon l'orientation du média, sa spécialisation, l'époque et la conjoncture sociale. De fait, la question du traitement de l'information culturelle va de pair, d'une certaine manière, avec la transformation du concept de culture.

Extraite de ce paradigme qui l'opposait à la nature, la culture s'est graduellement retrouvée, sous l'effet conjugué de diverses pensées rationalistes, en compagnie d'un nouvel ensemble de concepts pour expliquer le monde. Elle ne pouvait plus à elle seule expliquer l'activité humaine; ainsi, le politique, l'économique, le social se joignirent au culturel pour occuper l'espace qu'il prenait jadis seul. Et cela fut suffisant pour opérer progressivement sa disqualification de manière directement proportionnelle à la place que les autres "secteurs" prirent dans I'explication de notre vie quotidienne. Je n'ai pas besoin d'exposer longuement cet avancé, nous n'avons qu'à voir journellement jusqu'à quel point le politique et l'économique "habitent" notre vie.

Pendant tout ce temps, les communications se développèrent et transformèrent radicalement l'information; celle-ci devint un "monde" qui se donnait le mandat, quant à lui, non pas d'expliquer mais d'exposer le fonctionnement du monde. L'information présente la réalité, expose les rapports de force et les tendances en fonction du pouvoir qui régit la société et selon les positions que les différentes forces en présence définissent par rapport à ce pouvoir.

Le pouvoir, dans la société, appartient au monde politique et est axé sur le maintien d'un système économique; la culture est marginalisée, bien qu'on lui concède d'être l'essence de cette même société. Dans cet univers, la culture est surtout une question de production artistique, de divertissement, de variétés, de loisir, d'amusement entre deux périodes 
de travail. L'information s'y modèle et rend compte de cette conception de la culture.

Le "monde de l'information" est le premier à l'affirmer: l'information est un droit inaliénable. Toute société qui se refuse le droit à l'information est discriminatoire, totalitaire et antidémocratique. Mais est-ce le droit à toutes informations qui est inaliénable ou seulement le droit à l'information "politique"? II serait toujours possible d'alléguer qu'il s'agit là d'un choix collectif ou plus exactement du choix d'une collectivité dans la mesure où ses autorités imposent démocratiquement cette vision et que dans cette vision l'information a caractère politique est dominante; il s'agit d'un choix collectif dans la même mesure où les médias appartiennent idéologiquement à cette société et à son pouvoir et que ce sont eux qui ont I'autorité d'établir les contenus.

Je ne parle pas du choix d'une nouvelle particulière par rapport à une autre, mais du choix du contenu général des informations que le pouvoir politique crée et engendre par la reconnaissance prépondérante de son activité dans la société. Pour ce faire, I'information a ses règles implicites et explicites; la manchette tient habituellement du spectaculaire.

L'exercice du pouvoir est une activité "spectaculaire" parce que ses décisions influencent notre réalité matérielle immédiate. Seules les catastrophes sont en mesure de ravir la manchette aux politiciens. Nous nous mouvons à cet égard dans un univers de symboles dont nous ne soupçonnons pas toujours toutes les ramifications. La libre circulation des idées n'est pas non plus une donnée supra-politique, c'est aussi un concept affrété par le pouvoir et d'autant plus facile à récupérer qu'il semble tenir de la vertu... et personne ne peut être contre la vertu. Mais le pouvoir n'est pas apolitique et vertueux. L'information non plus.

Par ailleurs, si nous considérons la situation qui lui est faite, comment a été définie dans la pratique la place de la culture dans les médias? Premièrement, il faut distinguer l'analyse (critique ou affaires publiques), la chronique (type 
agenda des activités ou potins) et la nouvelle (le bulletin d'informations). Sur cette base, il sera possible pour quiconque de faire le tour de l'ensemble des médias afin d'évaluer le rang que chacun accorde à la culture, soit en lui allouant une place spécifique ou soit autrement, en lui ménageant de l'espace ou du temps d'information à travers des ensembles dont la thématique n'est pas prédéterminée.

Bien qu'il semble légitime de se demander si les médias, qu'ils soient écrits ou électroniques, ont une politique d'information culturelle bien définie, force est de reconnaître que cela ne semble pas être le cas lorsque nous nous mettons à suivre attentivement leurs activités; ou s'il en existe une, elle se résume probablement à ceci: "si on a le temps et si on a de la place". Parfois nous pouvons même nous demander si les médias ont une politique d'information tout simplement.

Cela revient à dire que l'information culturelle est laissée à la discrétion des journalistes; chacun, selon ses centres d'intérêt, sa formation, sa réflexion sur la culture, a la responsabilité d'assumer le droit à l'information culturelle, d'exposer à la société ses comportements, ses enjeux culturels. II en va alors de l'initiative individuelle ou presque d'assurer une équité, une justice dans la dispensation de l'information à l'intention de tous ceux et celles qui attendent un bon traitement desdites informations liées à leurs préoccupations.

Pour qui connaît un peu les conditions de travail de la plupart des journalistes, en particulier en région, il devient souvent difficile d'exiger beaucoup plus de leur part. Que faire alors? Se satisfaire de quelques pauvres excuses des responsables des médias? Si les excuses étaient valables pour la culture elles devraient l'être également pour l'économie ou la politique.

D'abord, il faut trouver les moyens de briser le cercle vicieux qui veut que les médias ne font pas d'information culturelle parce que les gens n'en veulent pas; reprenons la formule usée et réaffirmons que si les gens n'en veulent pas c'est tout simplement parce que les médias n'en font pas. À 
preuve, les chroniques du type Télex-arts qui ont toujours plus d'informations à diffuser que de temps pour le faire. II y a à peine deux ans, les autorités des médias croyaient encore que seul le sport avait des choses à dire.

Le monde de l'information est un monde critique et il se doit aussi d'être autocritique. Une question qui doit être posée, non pas obséquieusement mais de façon analytique, est la relation de l'information et de "la politique". La presse ne devrait-elle pas être inquiète de la dépendance de son contenu à l'égard de la politique, n'est-elle pas gênée de se laisser ainsi remorquer par une vision prédominante pour expliquer tout ce qui concerne la vie en société.

Qu'en est-il des médias de la région? Je ne ferai pas ici le tour de chacun d'eux. En utilisant les catégories de traitement proposées plus haut, il est possible de constater que la situation est faite, ici comme ailleurs, d'avances et de reculs. Alors que les médias nationaux semblent augmenter et stabiliser leurs moyens de traitement de l'information culturelle, les médias régionaux n'ont pas l'air de vouloir accentuer le virage alors qu'une certaine amélioration était visible depuis quelques années.

Dans le cadre actuel, il serait quand même possible de modifier les choses si la presse en général mettait autant d'énergies à rechercher et à comprendre les éléments d'intérêts collectifs qui existent dans les "dossiers culturels" qu'elle le fait dans d'autres cas. Débusquer l'information ne signifie pas seulement débusquer les dossiers inaccessibles. Souvent I'intérêt d'une information réside dans son seul traitement. Que I'on aille vers les groupes ou les individus, que I'on analyse l'événement, les tendances, les débats, les conflits, l'insolite des sujets qualifiés de culturels, de la même manière qu'on le fait pour des sujets dits sociaux ou économiques, et nous verrons que peut exister un traitement de l'information culturelle. Ainsi les bulletins d'informations ne seront pas monopolisés par la seule tourmente des politiciens.

II est bien entendu que personne n'osera croire que l'in- 
formation culturelle serait la seule façon d'expliquer nos problèmes de société. Si la libre circulation des idées n'est pas en soi une garantie de transparence dans l'analyse des faits sociaux, de rendre compte de nos comportements ou de nos productions culturels ne signifie pas que nous aurions trouvé la panacée.

La réclamation d'un droit à l'information culturelle provient sans doute d'une sorte de malformation de nos comportements sociétaux qui nous oblige à compartimenter nos activités. Chaque bestiole dans sa cage pour assurer le règne de la plus politicienne d'entre elles. Devant un tel problème, nous pouvons toujours imaginer un monde décloisonné, décompartimenté, où se ferait une intégration des ressources, une gestion faisant la part tant au culturel qu'à l'économique en fonction d'une explication pluridimensionnelle de la vie sociale. L'.information culturelle serait alors pleine et entière, se dit-on.

Tel monde idéal est encore loin d'exister; pas besoin d'attendre son avènement pour entreprendre des changements. Au fond nous en sommes presque réduits à réclamer des colonnes, des émissions d'information réservées à la culture parce que nous avons de plus en plus la preuve que les responsables des médias refusent de s'ouvrir à l'évidence de sa présence impérative. Nous voulons qu'on nous crée des ghettos, des isolats d'information comme le sport car nous désespérons de voir la situation se modifier sur le fond. Cette réclamation, elle est faite pour les milliers et les milliers de personnes qui investissent et s'investissent afin de décoder autrement que par les logiques politiques, économiques ou militaires les rapports de force que nous entretenons tous les jours et qui justifient les choix que nous faisons en tant que collectivité.

À cette trame de fond, comme un discours, viennent s'articuler les productions culturelles de tous les artistes et travailleurs culturels et dont nous avons, en toute équité, I'obligation de témoigner socialement. D'où les réclamations que cesse la monopolisation des moyens d'information, que 
nous payons tous d'une façon ou d'une autre, par les dominantes à caractère étroitement politique.

Disons qu'il est possible d'admettre théoriquement que tout est politique, que la vie privée est politique; mais lorsque le glissement s'effectue du politique à la politique comme c'est le cas dans l'action quotidienne, il semble nécessaire de revenir conventionnellement aux explications réductrices et cloisonnées de la réalité pour tenter d'expliquer comment il devrait être possible de faire justice à certaines activités humaines sur la scène publique. Voilà pourquoi il ne me semble pas inutile d'élaborer de telles argumentations en faveur de l'information culturelle. 


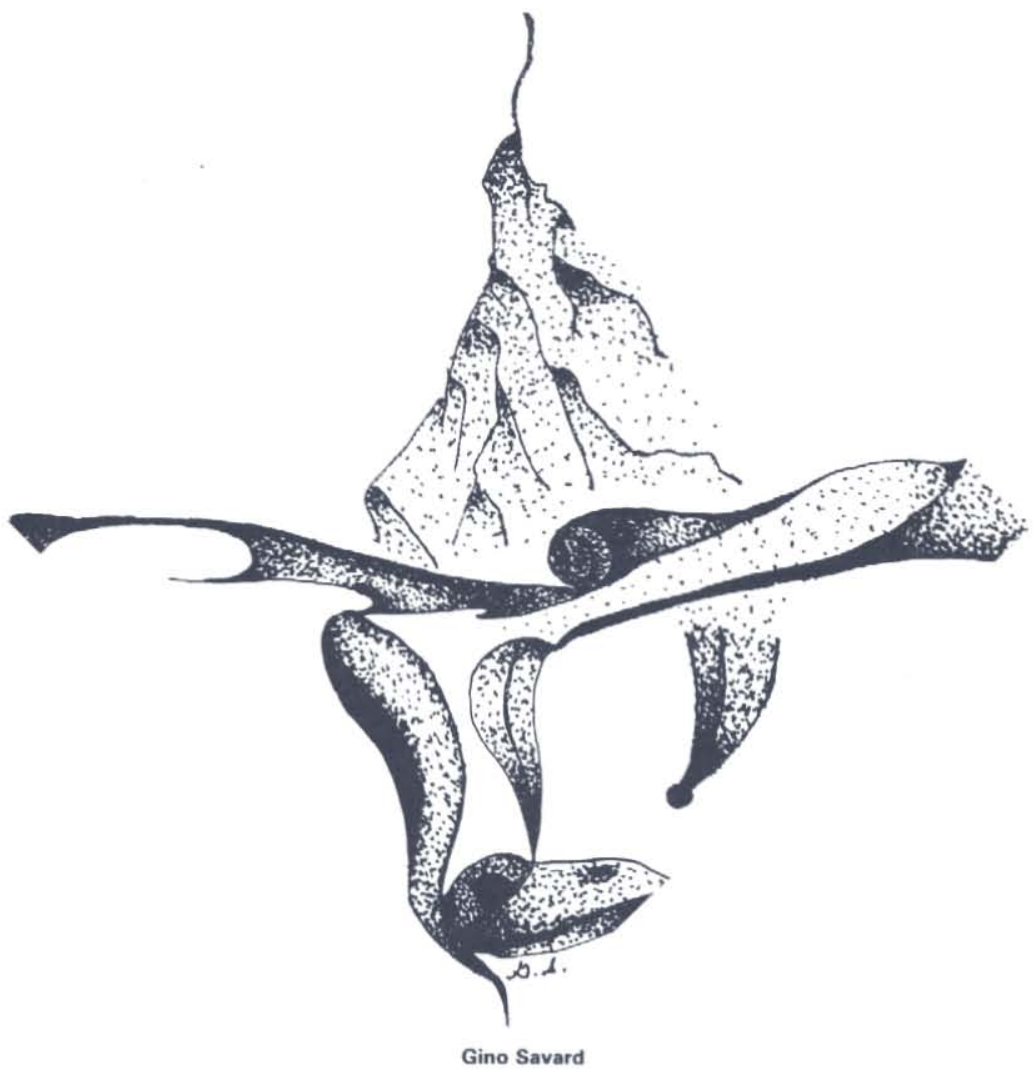

